\title{
Mutational Profiling of Driver Tumor Suppressor and Oncogenic Genes in Brazilian Malignant Pleural Mesotheliomas
}

\author{
Nathália C. Campanella ${ }^{a}$ Eduardo Caetano Silva $^{\mathrm{b}}$ Gustavo Dix $^{\mathrm{c}}$ \\ Fabiana de Lima Vazquez ${ }^{a}$ Flávia Escremim de Paulad \\ Gustavo N. Berardinellid Marcelo Balancin ${ }^{e}{ }^{f}$ Roger Chammas ${ }^{f}$ \\ Rossana V. Mendoza Lopez ${ }^{f}$ Henrique César S. Silveira ${ }^{a}$ \\ Vera Luiza Capelozzi ${ }^{\mathrm{e}}$ Rui Manuel Reis ${ }^{\mathrm{a}} \mathrm{g}, \mathrm{h}$
}

${ }^{a}$ Molecular Oncology Research Center, Barretos Cancer Hospital, Barretos, Brazil; b Department of Pathology, Barretos Cancer Hospital, Barretos, Brazil; ' Department of Surgery, Barretos Cancer Hospital, Barretos, Brazil;

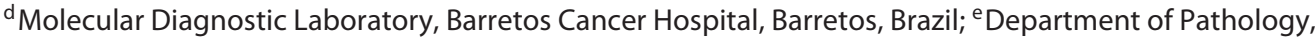

Faculty of Medicine, University of São Paulo, São Paulo, Brazil; ${ }^{f}$ Center for Translational Research in Oncology, Instituto do Câncer do Estado de São Paulo, São Paulo, Brazil; ${ }^{9}$ Life and Health Sciences Research Institute (ICVS), Medical School, University of Minho, Braga, Portugal; hICVS/3B's-PT Government Associate Laboratory,

Braga/Guimarães, Portugal

\section{Keywords}

Next-generation sequencing · Oncogenes · Tumor suppressor genes - Mutation · Malignant mesothelioma · Asbestos

\begin{abstract}
Background: Malignant pleural mesothelioma (MPM) is a highly lethal disease comprising a heterogeneous group of tumors with challenging to predict biological behavior. The diagnosis is complex, and the histologic classification includes 2 major subtypes of MPM: epithelioid ( $60 \%$ of cases) and sarcomatous ( $20 \%)$. Its identification depends upon pathological investigation supported by clinical and radiological evidence and more recently ancillary molecular testing. Treatment options are currently limited, with no known targeted therapies available. Objectives: To elucidate the mutation profile of driver tumor suppressor and oncogenic
\end{abstract}

genes in a cohort of Brazilian patients. Methods: We sequenced 16 driver genes in a series of 43 Brazilian malignant mesothelioma (MM) patients from 3 distinct Brazilian centers. Genomic DNA was extracted from formalin-fixed paraffin-embedded tumor tissue blocks, and the TERT promoter region was amplified by PCR followed by direct capillary sequencing. The Illumina TruSight Tumor 15 was used to evaluate 250 amplicons from 15 genes associated with solid tumors (AKT1, GNA11, NRAS, BRAF, GNAQ, PDGFRA, EGFR, KIT, PIK3CA, ERBB2, KRAS, RET, FOXL2, MET, and TP53). Library preparation with the TruSight Tumor 15 was performed before sequencing at the MiSeq platform. Data analysis was performed using Sophia DDM software. Results: Out of 43 MPM patients, 38 (88.4\%) were epithelioid subtype and 5 (11.6\%) were sarcomatoid histotype. Asbestos exposure was present in 15 (39.5\%) patients with epithelioid MPM and 3 (60\%) patients with sarcomatoid MPM. We found a TERT promoter mutation in $11.6 \%$ of MM, and the c. $-146 \mathrm{C}>\mathrm{T}$ mutation karger@karger.com

www.karger.com/pat

(C) 2020 S. Karger AG, Base

Karger"
Dr. Rui Manuel Reis

Molecular Oncology Research Center

Barretos Cancer Hospital, Rua Antenor Duarte Vilela, 1331

Barretos, SP 14784-400 (Brazil)

ruireis.hcb@gmail.com 
was the most common event. The next-generation sequencing was successful in 33 cases. A total of 18 samples showed at least 1 pathogenic, with a median of 1.8 variants, ranging from 1 to 6. The most mutated genes were TP53 and ERBB2 with 7 variants each, followed by NRAS BRAF, PI3KCA, EGFR and PDGFRA with 2 variants each. KIT, AKT1, and FOXL2 genes exhibited 1 variant each. Interestingly, 2 variants observed in the PDGFRA gene are classic imatinib-sensitive therapy. Conclusions: We concluded that Brazilian MPM harbor mutation in classic tumor suppressor and oncogenic genes, which might help in the guidance of personalized treatment of MPM.

(c) 2020 S. Karger AG, Basel

\section{Introduction}

Malignant pleural mesothelioma (MPM) is an aggressive tumor arising from mesothelial cells forming a lubricated and nonadhesive surface that cover and protect the lungs, abdomen, and heart [1-3]. MPM is a rare and a universally lethal cancer [4] in which the most common form arises in the pleura of the lung ( $80 \%$ of cases) $[1,2]$, and much more rarely in the peritoneum and tunica vaginalis [2]. Following the World Health Organization (WHO), the number of new MPM cases worldwide in 2018 was 30,443 , and the number of deaths was 25,576 [5]. In Brazil, there is an impressive lack of studies and an underreporting of MPM cases, making it difficult to make public health decisions [6]. Pedra et al. [7] studied MPM mortality in Brazil, from 1980 to 2003, and found the death frequency increased from an average of 68.4 per year in the 1980 s to 110 per year in the following decade, and 157 per year in 2000-2003.

MPM is a direct causal relationship between exposure to an environmental carcinogen, such as asbestos, and the transformation of mesothelial cells and the development of the tumor [2]. Asbestos is a generic name referring to a family of 6 mineral fibers, with high tensile strength and resistance to thermal and chemical degradation, very popular in the industry $[1,8]$. Although the use of asbestos has already been prohibited in 54 countries worldwide, its extraction and use are still ongoing in many developing countries as Russia, China, Kazakhstan, and Brazil $[2,9]$. One of the peculiarities of MPM is the long-term latency period between asbestos exposure and tumor development, ranging from about 25 to 40 years $[10,11]$.

Histologically, MPM are classified into 2 major types: epithelioid mesotheliomas, which constitute about $60 \%$ of mesotheliomas and have the most extended survival (12-27 months) and sarcomatoid mesotheliomas, which constitute around $20 \%$ of mesotheliomas and are characterized by their spindle cell morphology and have the worst survival (7-18 months) $[2,12,13]$.

For the last 15 years, first-line chemotherapy combines pemetrexed and cisplatin or pemetrexed and carboplatin [14]. The benefits are usually modest at best, and prognosis remains poor: the median survival is $<1$ year from the time of diagnosis $[10,11]$. Recently, the major advance in MPM treatment is the identification of bevacizumab in addition to pemetrexed and cisplatin chemotherapy, probably by modifying the tumor microvasculature $[2,15]$.

Genetic and epigenetic alterations are observed in mesothelial cells. The most frequently altered tumor suppressor genes are BRCA-associated protein 1 (BAP-1), neurofibromatosis type 2 (NF-2), cyclin-dependent kinase inhibitor 2A (CDKN2A), large tumor suppressor kinase 2 (LATS2), and SET domain containing 2 (SETD2) $[1,16]$. These alterations drive cell proliferation, resistance to apoptosis, and local immunosuppression, providing the rationale for some new targeted therapies nowadays $[17,18]$. Approximately $65 \%$ of mesotheliomas harbor inactivation of the tumor suppressor BAP1 and, although rare, germline mutation in $B A P 1$ confers a higher risk of mesothelioma development $[19,20]$. While several prognostic factors have been proposed, only a few have been independently validated.

Recently, genome-wide somatic mutations of MPM were profiled using next-generation sequencing (NGS) methods, identifying genomic subtypes harboring mutations in TP53, TERT, and other driver genes [16, 21]. Nevertheless, useful predictive biomarkers for therapy are yet to be found, increasing the need to elucidate and deepen the complexities of MPM biology and heterogeneity. In the present study, we evaluated the mutation profile of driver genes that are frequently mutated in solid tumors, in order to correlate the mutation status with malignant mesothelioma (MM) patients' clinical-pathological features and to identify potential clinically actionable genetic alterations in Brazilian MM.

\section{Materials and Methods}

Patients

Information on 43 patients diagnosed with MPM between 2008 and 2018 at Barretos Cancer Hospital (Barretos, SP, Brazil), Cancer Institute of São Paulo (ICESP; Sao Paulo, SP, Brazil) and from the files of a large reference pathology laboratory located in 
Table 1. Clinical characteristics of patients with malignant mesothelioma

\begin{tabular}{llll}
\hline Characteristic & $\begin{array}{l}\text { Epithelioid } \\
(n=38)\end{array}$ & $\begin{array}{l}\text { Sarcomatoid } \\
(n=5)\end{array}$ & $p$ value \\
\hline $\begin{array}{l}\text { Median age, years } \\
\text { Sex }\end{array}$ & 60 & 56 & 0.33 \\
$\quad$ Male & $26(68.4)$ & $1(20)$ & 0.45 \\
$\quad$ Female & $12(31.6)$ & $4(80)$ & \\
$\begin{array}{l}\text { Asbestos exposure } \\
\text { No }\end{array}$ & $23(60.5)$ & $2(40)$ & 0.51 \\
$\quad$ Yes & $15(39.5)$ & $3(60)$ & \\
$\begin{array}{l}\text { Topography } \\
\text { Pleural }\end{array}$ & $38(100)$ & $5(100)$ & \\
$\begin{array}{l}\text { TERT status } \\
\quad \text { Mutation }\end{array}$ & $5(15.2)$ & 0 & \\
$\quad$ Wild type & $28(84.8)$ & $5(100)$ & 0.94 \\
\hline
\end{tabular}

Data are presented as $n(\%)$ unless otherwise indicated.
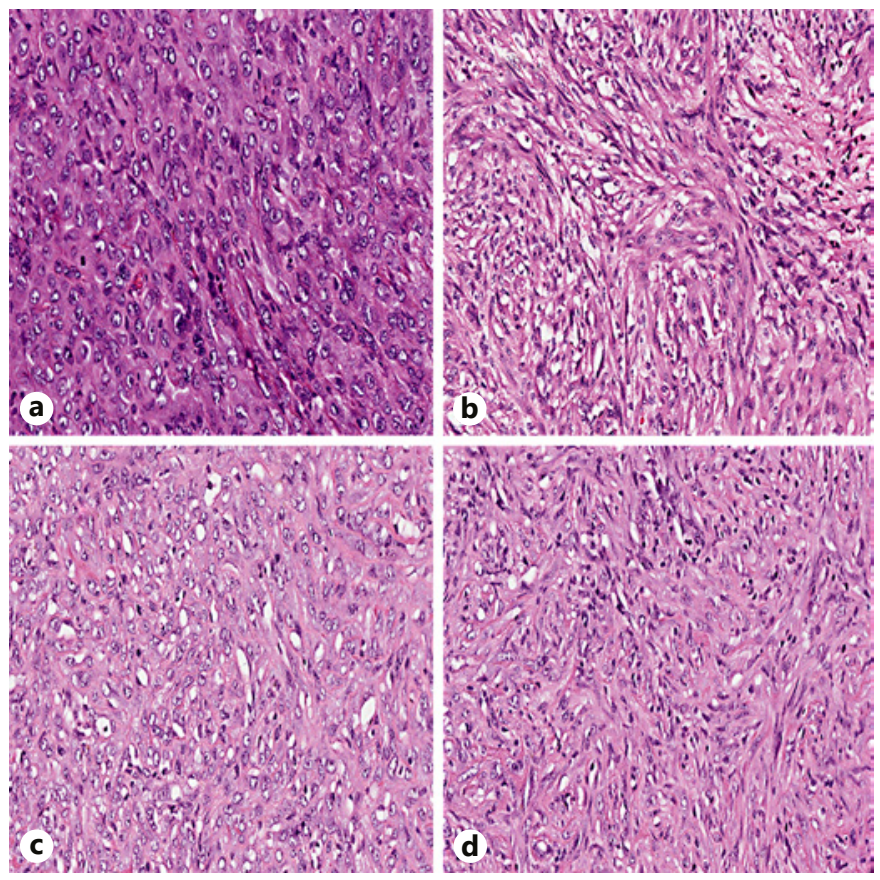

Fig. 1. Hematoxylin and eosin-stained slides of MPM, with different histologic classification: epithelioid (a), sarcomatoid (b), biphasic with the epithelioid component (c), and biphasic showing a sarcomatoid component (d). chemical, and immunohistochemical criteria [22]. As a positive marker of immunohistochemistry for MPM, we used calretinin, WT-1, cytokeratin 5/6, and D2-40. As negative markers for MPM, we used MOC31, BerEP4, and thyroid transcription factor-1. In cases whare positive mesothelial markers were not yet available, negative markers were used for making the diagnosis of MPM. A review of pathological reports and confirmation by 2 experienced pathologists yielded 38 epithelioid and 5 sarcomatoid MPM. Variables recorded in the database included age, gender, and histologic types (Table 1).

\section{Histologic Evaluation}

Two pathologists reviewed all available hematoxylin and eosinstained slides of MPM, which included a median of 9 slides per case. Histologic classification for epithelioid and sarcomatoid MPM was done according to the 2015 WHO classification [3] (Fig. 1).

\section{DNA Isolation}

Representative formalin-fixed paraffin-embedded tumor samples from 43 MPM patients were retrieved from the Pathology Department of Barretos Cancer Hospital. DNA from formalin-fixed paraffin-embedded tissues was retrieved from 10 - $\mu$ m cuts, after careful macrodissection of the tumor area using a sterile needle and ensuring the presence of $>50 \%$ of neoplastic cells. DNA was isolated using the QIAamp DNA Micro Kit (Qiagen, Germany) according to the manufacturer's instructions and as previously described by our group $[23,24]$. The quality and concentration of DNA were measured in a NanoDrop 2000 UV-Vis Spectrophotometer (Thermo Fisher Scientific, USA) or Qubit Fluorometric Quantitation (Thermo Fisher Scientific) followed by storage at $-20^{\circ} \mathrm{C}$ until molecular analysis.

\section{TERT Sanger Sequencing}

A fragment of the TERT promoter region was amplified in all 43 samples by PCR using the primers $5^{\prime}$-AGTGGATTCGCGGGCACAGA- $3^{\prime}$ and 5'-CAGCGCTGCCTGAAACTC- ${ }^{\prime}$, resulting in a PCR product of $235 \mathrm{bp}$, which contained the sites of the c. $-124 \mathrm{C}>\mathrm{T}$ and c. $-146 \mathrm{C}>\mathrm{T}$ mutations as previously described [25-27]. PCR was performed with an initial denaturation at $95^{\circ} \mathrm{C}$ for $15 \mathrm{~min}$, followed by 40 cycles of denaturation at $95^{\circ} \mathrm{C}$ for $30 \mathrm{~s}$, annealing at $64^{\circ} \mathrm{C}$ for $90 \mathrm{~s}$, elongation at $72^{\circ} \mathrm{C}$ for $30 \mathrm{~s}$, and final elongation at $72^{\circ} \mathrm{C}$ for $7 \mathrm{~min}$. The quality of PCR products was confirmed by gel electrophoresis. The sequencing of the PCR product was performed using the BigDye Terminator version 3.1 Cycle Sequencing Kit (Applied Biosystems, USA) and ABI PRISM $3500 \times$ L Genetic Analyzer (Applied Biosystems).

The sequencing reaction was performed in the forward direction. An independent PCR amplification/sequencing, in the forward direction, was performed in positive samples or samples that

NGS-based mutation analysis was performed using the Illumina TruSight Tumor 15 on the MiSeq instrument according to the manufacturer's instructions (Illumina, USA). It provides a mutation profile of 15 therapy driver genes AKT1, GNA11, NRAS, BRAF, GNAQ, PDGFRA, EGFR, KIT, PIK3CA, ERBB2, KRAS, RET, FOXL2, MET, and TP53. The read alignment and variant calling were performed with BaseSpace BWA Enrichment version 2.1 (Illumina) and Sophia DDM ${ }^{\circledR}$ software version 4.2 (Sophia Genetics SA, Switzerland). Several steps were used to filter variants were inconclusive.

\section{Targeted NGS}


Fig. 2. Electropherograms showing sequence of TERT promoter region with 2 hot-spot mutations c.-124C>T and c.$146 \mathrm{C}>\mathrm{T}$. a Heterozygous c. $-124 \mathrm{C}>\mathrm{T}$ TERT promoter mutation (arrow). b Heterozygous c. $-146 \mathrm{C}>\mathrm{T}$ TERT promoter mutation (arrow).

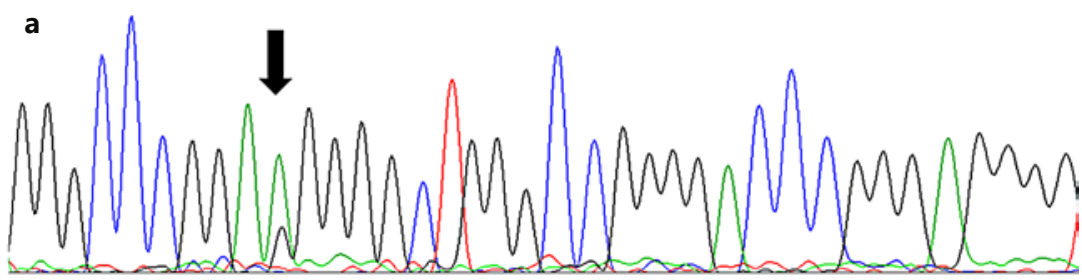

b

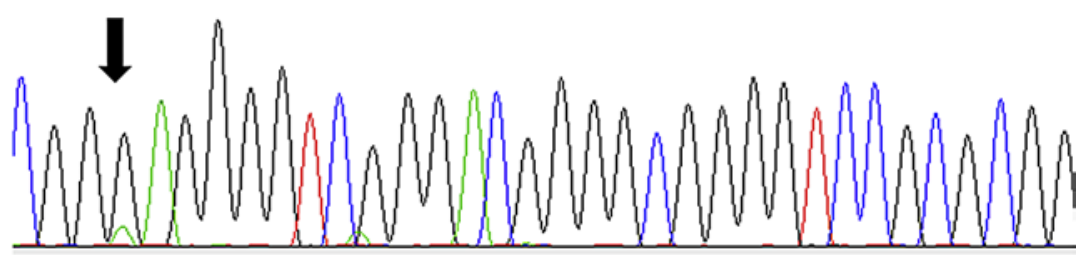

Table 2. TERT status and mutations according to histotype

\begin{tabular}{lll}
\hline TERTp status & Histotype & Mutated genes \\
\hline c.-146 C $>\mathrm{T}$ & Epithelioid & No \\
\hline c.-146 C $>\mathrm{T}$ & Epithelioid & Undetermined \\
\hline c.-146 C $>\mathrm{T}$ & Epithelioid & ERBB2 exon 29 (Pro1105Ser) \\
& & ERBB2 exon 21 (Gly674Arg) \\
& & PI3KCA exon 21 (*Arg1023Gln) \\
& & TP53 exon 6 p. (Gly187Val) \\
\hline
\end{tabular}

\begin{tabular}{lll}
\hline c.-124 C>T & Epithelioid & TP53 exon 6 p. (Leu194Arg) \\
\hline c.-124 C>T & Epithelioid & TP53 exon 8 p. (Glu294*) \\
\hline
\end{tabular}

identified in the screening. First, intronic variants and synonymous single nucleotide variants (SNVs) were excluded. Subsequently, polymorphisms were excluded using the frequency of $1 \%$ in both databases - 1000 Genomes Project and GO Exome Sequencing Project (ESP5400). Finally, this set was further filtered by excluding all variants showing a poor quality (read depth $<500 \times$ ), low variant allele frequency (variant frequency analysis $<10 \%$ ), and without clinical significance available in Sophia DDM ${ }^{\circledR}$ software version 4.2 (Sophia Genetics SA). In addition, 10 bp were considered in the initial and final portion of introns for variant analyses at the splice site of each exon.

\section{Results}

\section{Cohort Description}

The clinical characteristics of the patients in our MPM cohort are summarized in Table 1 by histologic type. Out of 43 MPM patients, 38 (88.4\%) were epithelioid subtype and $5(11.6 \%)$ were sarcomatoid histotype. A similar distribution of age and sex was found between the histologic types. Asbestos exposure was present in 15 (39.5\%) patients with epithelioid MPM and $3(60 \%)$ patients with sarcomatoid MPM. Pleural topography was found in 38 (100\%) patients with epithelioid histology and 5 (100\%) patients with sarcomatoid histology.

\section{Mutation Profile}

We found a TERT promoter mutation in $11.6 \%(5 / 43)$ of the MPM (Table 2; Fig. 2). The c.-146C $>$ T mutation was present in 3 cases and the c. $-124 \mathrm{C}>\mathrm{T}$ mutation in 2 cases. The 2 mutations occur in a mutually exclusive manner. All TERT mutated cases were histologically classified as epithelioid (Table 2).

In NGS-based mutation analysis, only 33 samples were successfully sequenced due to DNA quality issues. A total of 18 samples showed at least 1 variant (54.5\%), and the number of variants per sample ranged from 1 to 6 , with a median of 1.8 variants (Table 3 ). The top altered genes were as follows: TP53 with 7 different variants in 7 cases (7/33 cases representing 21.2\%), ERBB2 with 7 different variants in 6 cases $(6 / 33 ; 18.2 \%), B R A F$ and PDGFRA with 2 variants in 2 cases each $(2 / 33 ; 6 \%), N R A S$ and $E G F R$ with 2 variants in 1 case each $(1 / 33 ; 3 \%)$, and KIT, AKT1, PIK$3 C A$, and FOXL2 with 1 variant each $(1 / 33 ; 3 \%$; Table 3$)$.

Fourteen samples showed 1 variant $(77.7 \%), 2$ samples showed 2 variants (11.1\%), one sample showed 3 variants (5.6\%), and 1 sample showed 6 variants (5.6\%; Table 3 ). In total, 27 different variants were identified: 23 were missense, 2 nonsense, and 2 frameshift (Table 3 ). In addition, 24 were SNVs and 3 INDELs. In summary, 10 of the 27 


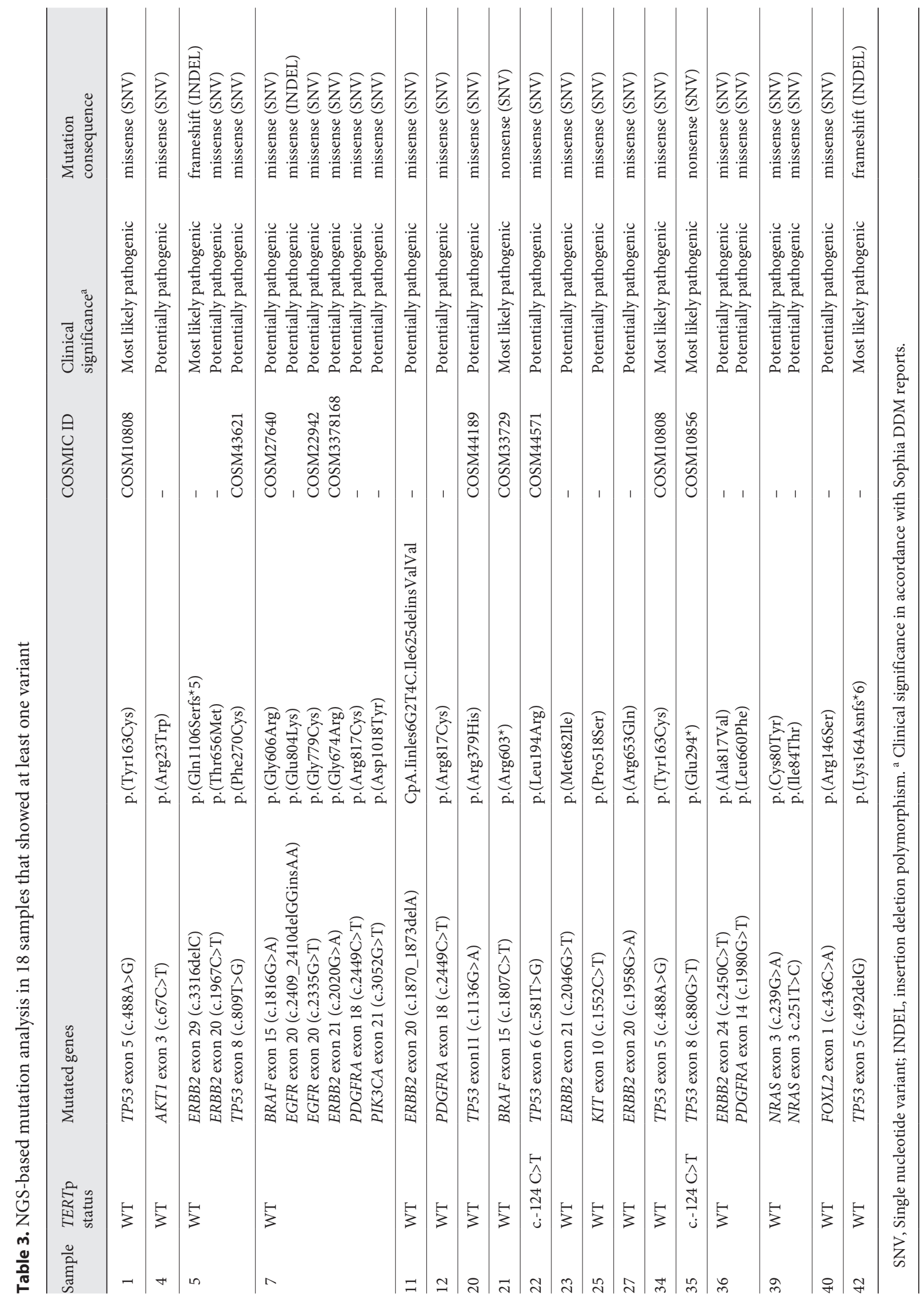


variants are known COSMICs (catalog of somatic mutations in cancer), and 21 were reported as potentially pathogenic and 6 as most likely pathogenic in accordance with Sophia DDM reports (Table 3).

To assess the therapeutic implications of molecular events in our set of variants, we used Database of Evidence for Precision Oncology (DEPO; http://depodinglab.ddns.net) that focuses on specific mutations (STAR Methods) and casts therapeutic projections based on FDA-approved therapies, clinical trials, and published clinical evidence [28]. Of note, 2 variants in the PDGFRA gene (p.[Arg817Cys] in exon 18 and p.[Leu660Phe] in exon 14) found in MM were already described as a target of imatinib and an FDA-approved targeted therapy for GIST patients.

\section{Discussion/Conclusion}

MPM is a lethal cancer of the lung caused by human exposure to asbestos fibers [29]. Asbestos fibers may be inhaled by workers who deal directly with the fibers, by family members who are unintentionally exposed through workers' clothing, and by inhabitants of areas close to work sites where asbestos is processed or used [7]. In the year 2000, only 6 countries were responsible for almost all global asbestos production. Brazil is among these countries and produces approximately 250,000 tons/year, which ranks Brazil as the third greatest worldwide asbestos consumer [7].

MPM is highly refractory to conventional therapies, and the median survival of patients is 9-12 months after diagnosis, even with a combination of aggressive surgical intervention and multimodality strategies $[1,29]$. Recently, MPM studies have identified genetic subtypes with a distinct profile of alterations in driver genes, increasing the need for understanding MPM biology for the successful development of personalized therapeutic modalities.

We analyzed the mutational profile in 16 driver genes by NGS or Sanger sequencing in 43 Brazilian MPM. Using Sanger sequencing, we analyzed TERT promoter mutations and found $11.6 \%$ mutated tumors. The c. $-146 \mathrm{C}>\mathrm{T}$ mutation was present in $7 \%$ and c. $-124 \mathrm{C}>\mathrm{T}$ in $4.6 \%$ of MPM. The 2 mutations occur in a mutually exclusive manner, and all TERT-mutated samples were histologically classified as epithelioid mesothelioma. In 2014, Tallet et al. [21] analyzed 132 MM and found $15.2 \%$ of TERT mutation (20/132), all in the c.-124 C>T region, and with a higher frequencyin sarcomatoid histologic subtype. They screened TERT promoter mutations by Sanger sequencing and in-

Mutational Profiling in Brazilian

Malignant Pleural Mesotheliomas cluded 61 samples derived from MM culture cells and 71 from tumor samples. Considering only the tumor samples, they found a mutation frequency similar to ours $-11.3 \%$ of the tumors had TERT promoter mutation.

In NGS-based mutation analysis, we found a total of 18 samples that showed at least 1 variant (representing $54.5 \%$ in a total of 33 cases studied). The range of variants was from 1 to 6 per sample, with a median of 1.8 variants. In total, 27 different variants were identified, and TP53 and $E R B B 2$ were the most altered genes with 7 different variants each.

Mutations in TP53 have been reported in MPM. Previous studies reported a range of TP53 mutations from 5.7 to $19 \%$ in MPM cases [16, 29-34]. Here, we found $21.2 \%$ of cases with TP53 mutation. In 2016, Bueno et al. [29] published a large series with 202 MPM cases and found TP53 mutations in $8 \%$ of cases. Recently, a TCGA cohort comprising 74 tumors revealed $13.5 \%$ of TP53 mutations [16]. Hmeljak et al. [16] showed that TP53 is one of the MPM driver genes, together with BAP1, SETD2, and NF2, and is associated with aggressive behavior $[16,28]$. They showed 13 TP53 mutations, mainly SNV type, missense type, and in exons 5-8 (all these alterations were found in $10 / 13$ mutated cases), as found by us, but in different nucleotides [16]. Interestingly, they suggested that TP53 mutations occur early and presumably permit the catastrophic loss of chromosomes [16]. Here, we confirmed the impact of TP53 mutations in many MPM cases (about 21\%), but we did not evaluate BAP1, SETD2, and NF2 genes.

Additionally, by targeted NGS, we found $18.2 \%$ of cases with at least 1 variant in the ERBB2 gene. Despite $E R B B 2$ mutations occurring in multiple cancers [28], this is the first report in MPM. ERBB2 is a member of the human epidermal growth factor receptor (HER) family of receptor tyrosine kinases, of which overexpression results in the oncogenic transformation of cells [35]. The ERBB2 gene is amplified in $15-20 \%$ of breast cancers and is associated with aggressive disease behavior [35]. It is known that some mutations in the ERBB2 transmembrane domain, mainly in the 656-660 region in protein sequence, promote significant cell survival by increasing the stability of the receptor and keeping it in its activated state [28]. Interestingly, here, we found 2 ERBB2 mutations specifically localized in 656 and 660 residues.

Other variants found in MPM cases were PDGFRA, $B R A F, N R A S$, and EGFR with 2 variants each, and KIT, $A K T 1, P I K 3 C A$, and FOXL2 with one variant each. Searching for mutations that are targeted by drugs that are now available, we used the DEPO platform and found 2 variants in PDGFRA (p.[Arg817Cys] in exon 18 and 
p.[Leu660Phe] in exon 14), targeted by imatinib that could improve outcomes for patients with mesothelioma. In accordance, Bailey et al. [28] also found that very few MM mutations are druggable (using DEPO, they found $1 \%)$. In addition, they found in about $50 \%$ of cases that the nucleotide changes occur in $\mathrm{C}>\mathrm{T}$. Here, we found that almost $30 \%$ of nucleotide changes occurred in $\mathrm{C}>\mathrm{T}$.

One limitation of our study is that we did not have the opportunity to correlate the asbestos exposure history from MPM cases with the clinical pathological and mutational profile.

In conclusion, we showed that MPM are highly complex and heterogeneous neoplasms. By Sanger sequencing and targeted NGS, we described a somatic mutation profile composed of the top altered genes TP53, ERBB2, and TERT. Interestingly, clinically actionable alterations were found in 2 cases, suggesting that these patients could benefit from this therapeutic modality.

\section{Acknowledgments}

We thank Barretos Cancer Hospital and the Public Ministry of Labor Campinas (Research, Prevention, and Education of Occupational Cancer Project), Campinas, Brazil, for partially funding the present study for Scientific and Technological Development (CNPq, Brazil). N.C. Campanella was a recipient of a Postdoctoral Fellowship (2016/03634-9) from the Fundaço de Amparo a Pesquisada do Estado de São Paulo (FAPESP)

\section{Statement of Ethics}

This study was approved by the local Ethics Committees (CEP$1033 / 2015$ ), and due to the retrospective nature of the study design signed patient consent was waived.

\section{Disclosure Statement}

The authors declare no competing financial interests.

\section{Funding Sources}

The Public Ministry of Labor Campinas (Research, Prevention, and Education of Occupational Cancer Project), Campinas, Brazil, partially funding the present study for Scientific and Technological Development (CNPq, Brazil). N.C. Campanella was a recipient of a Postdoctoral Fellowship (2016/03634-9) from the Fundação de Amparo a Pesquisada do Estado de São Paulo (FAPESP).

\section{Author Contributions}

N.C.C. and R.M.R. wrote the manuscript. R.M.R. designed the study. E.C.S., G.D., F.L.V., M.B., R.C., R.V.M.L., H.C.S.S., and V.L.C. organized and/or reviewed the clinical samples. N.C.C., F.E.P., and G.N.B. performed the experiments. N.C.C., G.N.B., F.E.P., and R.M.R. contributed to data analysis and interpretation. All authors reviewed the manuscript.

\section{References}

1 Sekido Y. Molecular pathogenesis of malignant mesothelioma. Carcinogenesis. 2013 Jul; 34(7):1413-9.

2 Yap TA, Aerts JG, Popat S, Fennell DA. Novel insights into mesothelioma biology and implications for therapy. Nat Rev Cancer. 2017 Jul;17(8):475-88.

3 Travis WD, Brambilla E, Burke AP, Marx A, Nicholson AG. WHO classification of tumours of the lung, pleura, thymus and heart. Lyon: International Agency for Research on Cancer; 2015.

4 Bianchi C, Bianchi T. Malignant mesothelioma: global incidence and relationship with asbestos. Ind Health. 2007 Jun;45(3):379-87.

5 Bray F, Ferlay J, Soerjomataram I, Siegel RL, Torre LA, Jemal A. Global cancer statistics 2018: GLOBOCAN estimates of incidence and mortality worldwide for 36 cancers in 185 countries. CA Cancer J Clin. 2018 Nov;68(6):394-424

6 Pinheiro GA, Antão VC, Monteiro MM, Capelozzi VL, Terra-Filho M. Mortality from pleural mesothelioma in Rio de Janeiro, Brazil, 1979-2000: estimation from death certificates, hospital records, and histopathologic assessments. Int J Occup Environ Health. 2003 Apr-Jun;9(2):147-52.

7 Pedra F, Tambellini AT, Pereira BB, da Costa AC, de Castro HA. Mesothelioma mortality in Brazil, 1980-2003. Int J Occup Environ Health. 2008 Jul-Sep;14(3):170-5.

8 Lagniau S, Lamote K, van Meerbeeck JP, Vermaelen KY. Biomarkers for early diagnosis of malignant mesothelioma: do we need another moonshot? Oncotarget. 2017 May; 8(32): 53751-62.

9 Zauderer MG, Krug LM. Novel therapies in phase II and III trials for malignant pleural mesothelioma. J Natl Compr Canc Netw. 2012 Jan;10(1):42-7.

10 Carbone M, Ly BH, Dodson RF, Pagano I, Morris PT, Dogan UA, et al. Malignant mesothelioma: facts, myths, and hypotheses. J Cell Physiol. 2012 Jan;227(1):44-58.

11 Carbone M, Kratzke RA, Testa JR. The pathogenesis of mesothelioma. Semin Oncol. 2002 Feb;29(1):2-17.

12 Attanoos RL, Gibbs AR. Pathology of malignant mesothelioma. Histopathology. 1997 May;30(5):403-18.
13 Burke K, Smid M, Dawes RP, Timmermans MA, Salzman P, van Deurzen CH, et al. Using second harmonic generation to predict patient outcome in solid tumors. BMC Cancer. 2015 Nov; 15(1):929.

14 Baas P, Fennell D, Kerr KM, Van Schil PE, Haas RL, Peters S; ESMO Guidelines Committee. Malignant pleural mesothelioma: ESMO Clinical Practice Guidelines for diagnosis, treatment and follow-up. Ann Oncol. 2015 Sep;26 Suppl 5:v31-9.

15 Zalcman G, Mazieres J, Margery J, Greillier L, Audigier-Valette C, Moro-Sibilot D, et al.; French Cooperative Thoracic Intergroup (IFCT). Bevacizumab for newly diagnosed pleural mesothelioma in the Mesothelioma Avastin Cisplatin Pemetrexed Study (MAPS): a randomised, controlled, openlabel, phase 3 trial. Lancet. 2016 Apr; 387(10026):1405-14.

16 Hmeljak J, Sanchez-Vega F, Hoadley KA, Shih J, Stewart C, Heiman D, et al.; TCGA Research Network. Integrative molecular characterization of malignant pleural mesothelioma. Cancer Discov. 2018 Dec;8(12):1548-65. 
17 Robinson BW, Musk AW, Lake RA. Malignant mesothelioma. Lancet. 2005 Jul; 366(9483):397-408.

18 Scherpereel A, Wallyn F, Albelda SM, Munck C. Novel therapies for malignant pleural mesothelioma. Lancet Oncol. 2018 Mar;19(3): e161-72.

19 Dey A, Seshasayee D, Noubade R, French DM, Liu J, Chaurushiya MS, et al. Loss of the tumor suppressor BAP1 causes myeloid transformation. Science. 2012 Sep;337(6101): 1541-6.

20 Kadariya Y, Cheung M, Xu J, Pei J, Sementino E, Menges CW, et al. Bap1 is a bona fide tumor suppressor: genetic evidence from mouse models carrying heterozygous germline Bap1 mutations. Cancer Res. 2016 May;76(9): 2836-44.

21 Tallet A, Nault JC, Renier A, Hysi I, GalateauSallé F, Cazes A, et al. Overexpression and promoter mutation of the TERT gene in malignant pleural mesothelioma. Oncogene. 2014 Jul;33(28):3748-52.

22 Galateau-Salle F, Churg A, Roggli V, Travis WD; World Health Organization Committee for Tumors of the Pleura. The 2015 World Health Organization classification of tumors of the pleura: advances since the 2004 classification. J Thorac Oncol. 2016 Feb;11(2):142-54.

23 Campanella NC, Penna V, Ribeiro G, Abrahão-Machado LF, Scapulatempo-Neto C, Reis RM. Absence of microsatellite instability in soft tissue sarcomas. Pathobiology. 2015;82(1):36-42.
24 Yamane LS, Scapulatempo-Neto C, Alvarenga L, Oliveira CZ, Berardinelli GN, Almodova $\mathrm{E}$, et al. KRAS and BRAF mutations and MSI status in precursor lesions of colorectal cancer detected by colonoscopy. Oncol Rep. 2014 Oct;32(4):1419-26.

25 Batista R, Cruvinel-Carloni A, Vinagre J, Peixoto J, Catarino TA, Campanella NC, et al. The prognostic impact of TERT promoter mutations in glioblastomas is modified by the rs2853669 single nucleotide polymorphism. Int J Cancer. 2016 Jul;139(2):414-23.

26 Campanella NC, Celestino R, Pestana A, Scapulatempo-Neto C, de Oliveira AT, Brito $\mathrm{MJ}$, et al. Low frequency of TERT promoter mutations in gastrointestinal stromal tumors (GISTs). Eur J Hum Genet. 2015 Jun;23(6): 877-9.

27 Bailey MH, Tokheim C, Porta-Pardo E, Sengupta $\mathrm{S}$, Bertrand $\mathrm{D}$, Weerasinghe $\mathrm{A}$, et al.; MC3 Working Group; Cancer Genome Atlas Research Network. Comprehensive characterization of cancer driver genes and mutations. Cell. 2018 Apr;173(2):371-385. e18.

28 Pahuja KB, Nguyen TT, Jaiswal BS, Prabhash $\mathrm{K}$, Thaker TM, Senger K, et al. Actionable activating oncogenic ERBB2/HER2 transmembrane and juxtamembrane domain mutations. Cancer Cell. 2018 Nov;34(5):792-806. e5.

29 Bueno R, Stawiski EW, Goldstein LD, Durinck S, De Rienzo A, Modrusan Z, et al. Comprehensive genomic analysis of malignant pleu- ral mesothelioma identifies recurrent mutations, gene fusions and splicing alterations. Nat Genet. 2016 Apr;48(4):407-16.

30 Altomare DA, Vaslet CA, Skele KL, De Rienzo A, Devarajan K, Jhanwar SC, et al. A mouse model recapitulating molecular features of human mesothelioma. Cancer Res. 2005 Sep; 65(18):8090-5.

31 Bott M, Brevet M, Taylor BS, Shimizu S, Ito T, Wang $\mathrm{L}$, et al. The nuclear deubiquitinase BAP1 is commonly inactivated by somatic mutations and 3p21.1 losses in malignant pleural mesothelioma. Nat Genet. 2011 Jun; 43(7):668-72.

32 Guo G, Chmielecki J, Goparaju C, Heguy A, Dolgalev I, Carbone M, et al. Whole-exome sequencing reveals frequent genetic alterations in BAP1, NF2, CDKN2A, and CUL1 in malignant pleural mesothelioma. Cancer Res. 2015 Jan;75(2):264-9.

33 Shukuya T, Serizawa M, Watanabe M, Akamatsu $\mathrm{H}$, Abe $\mathrm{M}$, Imai $\mathrm{H}$, et al. Identification of actionable mutations in malignant pleural mesothelioma. Lung Cancer. 2014 Oct;86(1): $35-40$.

34 Kim JE, Kim D, Hong YS, Kim KP, Yoon YK, Lee $\mathrm{DH}$, et al. Mutational profiling of malignant mesothelioma revealed potential therapeutic targets in EGFR and NRAS. Transl Oncol. 2018 Apr;11(2):268-74.

35 Ursini-Siegel J, Schade B, Cardiff RD, Muller WJ. Insights from transgenic mouse models of ERBB2-induced breast cancer. Nat Rev Cancer. 2007 May;7(5):389-97. 